ORIGINAL ARTICLE

\title{
Passenger seating position and the risk of passenger death in traffic crashes: a matched cohort study
}

\author{
K M Smith, P Cummings
}

Injury Prevention 2006;12:83-86. doi: 10.1136/ip.2005.010306

See end of article for authors' affiliations .....................

Correspondence to: Dr K M Smith, Harborview Injury Prevention and Research Center, 325

Ninth Avenue, Box 359960, Seattle, WA 98104, USA; kaths@ u.washington.edu

Accepted 17 January 2006
Objective: To estimate the association of passenger seating position with the risk of death for passengers in traffic crashes.

Design, setting, participants: Matched cohort analysis of data from the National Highway Traffic Safety Administration Fatality Analysis Reporting System regarding 56644 passengers in 23308 passenger cars, light trucks, vans, and sport utility vehicles that crashed during 1990-2001.

Main outcome measure: The adjusted risk ratio (aRR) for death of a rear seat passenger compared with a front seat passenger within 30 days of a crash.

Results: The aRR for all passengers in the rear seat in a crash was 0.79 ( $95 \% \mathrm{Cl} 0.77$ to 0.82 ). This estimate varied by age, restraint use, and the presence of a front passenger airbag $(p<0.001)$. For restrained passengers in cars with a front passenger airbag, the aRR was $0.62(95 \% \mathrm{Cl} 0.48$ to 0.81$)$ for children $0-12$ years, 0.96 (95\% Cl 0.88 to 1.06$)$ for passengers $13-29$ years, 1.03 (95\% Cl 0.93 to 1.15 ) for passengers $30-59$ years, and $1.06(95 \% \mathrm{Cl} 0.90$ to 1.26$)$ for passengers 60 years or older. The rear seat was associated with more protection in cars without front airbags and more protection for unrestrained passengers compared with restrained passengers.

Conclusions: Previous studies have reported that the rear seat was safer for persons of all ages; thus seating a young child in the rear has often meant that older children and adults had to assume an increased risk of death by sitting in the front. These results suggest that when front passenger airbags are present and passengers are restrained, putting adults in front and children in back enhances child safety without sacrificing adult safety.
$\mathrm{P}$ revious studies have estimated that sitting in the rear seat as opposed to the front seat may reduce the risk of passenger death in a traffic crash: estimates of risk reduction range from $26 \%$ to $41 \% .^{1-5}$ Some of these studies had limited ability to control for possible confounding or had limited power to examine how the estimated association varied with age or other factors. Few of these studies examined how this possible protection may have changed with the introduction of front seat airbags.

The risk ratio for death for passengers in the rear seat, compared with the front seat, may be estimated using matched cohort methods. By estimating associations among passengers who crashed in the same vehicle, this design removes confounding by vehicle make, model, crash speed, and other measures of crash severity. ${ }^{67}$ Individual-level factors such as age, gender, seat belt use, airbag presence, and seat position may vary among passengers in the same car, but we can control for these factors with regression methods. ${ }^{7}$ The main purpose of this study was to estimate the association between seating position and death in a traffic crash using a matched cohort design. In addition to estimating the average association for seating position, we wished to estimate how that association varied by age, seat belt use, and the presence of an airbag for the front passenger. We also estimated restraint effectiveness by seat position, age, and airbag presence, as few studies have estimated rear seat restraint effectiveness.

\section{METHODS}

The National Highway Traffic Safety Administration operates the Fatality Analysis Reporting System (FARS) that collects information regarding all US crashes on public roads that result in a fatality within 30 days. ${ }^{8}$ We selected all passenger vehicles that crashed in 1990 through 2001 in which there were two or three passengers (in the right front, left rear, or right rear seat) and at least one person died among the passengers selected. Motor vehicle crashes in which all the passengers survived are not usually in the FARS data; however, these vehicles are not needed to estimate the average risk ratio for all crashes when matched cohort methods are used. ${ }^{9}$ We included passenger cars, minivans, large vans, light trucks with a second row of seats, and sport utility vehicles produced in model years 1975 through 2001. Vehicles in which passengers were riding in a non-passenger area such as a truck bed or cargo area were excluded. Vehicles were excluded if they had passengers in seat positions other than the right front, left rear, or right rear. Since information about airbags is often missing in FARS data, we used software that can ascertain airbag presence from the vehicle identification number. ${ }^{10}$

\section{Missing data}

A total of 56644 passengers in 23308 vehicles were selected for the study; however, $16 \%$ of vehicles were missing some information about restraint use, sex, age, or airbag presence. We used multiply imputed data available on the Harborview Injury Prevention and Research Center website for 1990-2001 to account for the missing data. ${ }^{11}$ We computed confidence intervals that accounted for both the variance within each imputed data set and the variance between the 10 imputed data sets. ${ }^{12}$

Publicly available data without identifiers were used and therefore the University of Washington Human Subjects Review Committee exempted the study from review.

Abbreviation: FARS, Fatality Analysis Reporting System. 
Table 1 Characteristics of passengers by seat position

\begin{tabular}{lll}
\hline Characteristic & $\begin{array}{l}\text { Rear seat, } \mathbf{n = 3 4 0 7 7} \\
(60 \%)\end{array}$ & $\begin{array}{l}\text { Front seat, } \mathbf{n = 2 2 5 6 7} \\
(\mathbf{4 0 \%})\end{array}$ \\
\hline Male & $18462(54 \%)$ & $11365(50 \%)$ \\
Age (years) & $7600(22 \%)$ & $1601(7 \%)$ \\
$0-12$ & $17291(51 \%)$ & $12049(53 \%)$ \\
$13-29$ & $5232(15 \%)$ & $5500(24 \%)$ \\
$30-59$ & $3954(12 \%)$ & $3417(15 \%)$ \\
$\geq 60$ & $11643(34 \%)$ & $11449(51 \%)$ \\
Restraint used & $0(0 \%)$ & $4128(18 \%)$ \\
Airbag present & $15686(46 \%)$ & $12754(57 \%)$ \\
Deaths & & \\
\hline
\end{tabular}

\section{Main study exposure: seating position}

We studied passengers in the right front seat (front seat) and in the right and left rear seat positions (rear seat). Drivers were not included in our study as there is no expectation that drivers might sit in any other seat position to reduce their risk of death. We limited our analysis to passenger seat positions only, as passengers have the option of sitting in the front or rear seat.

\section{Secondary exposure: restraint use}

Restraint use was categorized as restrained or unrestrained. Passengers were classified as restrained if they were using a lap belt, shoulder belt, lap and shoulder belt, or a child safety seat.

\section{Outcome}

The outcome in this study was death within 30 days of a traffic crash.

\section{Potential confounding variables}

Variables that we treated as potential confounders in the seat position analysis included passenger age (in years), passenger sex, and restraint use. We adjusted for age using 10 categories $(0-4,5-12,13-18,19-29,30-39,40-49,50-59$, $60-69,70-74$, and 75 or more years) using quadratic splines with knots at age category divisions and the tails restricted to be linear. ${ }^{13}$

\section{Statistical methods}

We estimated the adjusted risk ratios (aRRs) for death in a traffic crash for rear seat passengers compared with front seat passengers and for restrained passengers compared with unrestrained passengers using conditional Poisson regression. ${ }^{7}$ The aRRs were estimated by comparing passengers who crashed in the same vehicle, thereby controlling for vehicle and crash characteristics. We assessed whether our estimates of the effect of seat position varied by passenger sex, age (categorized as $0-12,13-29,30-59$, and 60 or more years), restraint use, and front passenger airbag presence. To evaluate statistical interaction terms in the regression models, we used the likelihood ratio test. The analysis was performed using Stata statistical software version 9.1. ${ }^{14}$

\section{RESULTS}

The final study sample consisted of 56644 passengers in 23308 vehicles; $60 \%$ of the passengers were in the rear seat and $40 \%$ were front seat passengers. There were 28440 deaths in the study sample; $46 \%$ of rear seat passengers and $57 \%$ of front seat passengers died (table 1). Restraints were used by $34 \%$ of rear seat passengers compared with $51 \%$ of front seat passengers. The mean ages of rear and front seat passengers were 26 and 33 years, respectively. Rear seat passengers were more often male (54\%) compared with 50\% of front seat passengers. Among front seat passengers, 18\% had an airbag present.

Accounting for matching in the vehicles and after adjustment for age, sex, and restraint use, the rear seat position was associated with a lower risk of death compared with the front seat: $\mathrm{aRR}=0.79$ (95\% CI 0.77 to 0.82). Airbag presence was not adjusted for since it was always perfectly correlated with front seat position within each car.

We found evidence that the effect of the rear seat position varied by age, restraint use, and the presence of a front passenger airbag $(\mathrm{p}<0.001)$ (table 2$)$. The risk of death for a rear passenger, compared with a front passenger of the same age, was reduced most among children and among passengers who were unrestrained. For rear seat passengers younger than 13 years compared with front seat passengers of the same age the aRR was 0.71 (95\% CI 0.64 to 0.79 ) for unrestrained passengers in vehicles without an airbag and 0.53 (95\% CI 0.41 to 0.70 ) for unrestrained passengers in vehicles with a front passenger airbag. For restrained passengers younger than 13 years, the aRR was 0.83 (95\% CI 0.75 to 0.92 ) for passengers in vehicles without an airbag and 0.62 (95\% CI 0.48 to 0.81 ) for passengers in vehicles with a front passenger airbag. For rear seat passengers 60 years or older compared with front seat passengers of the same age the aRR was 0.88 (95\% CI 0.80 to 0.96 ) for unrestrained passengers in vehicles without an airbag and 0.91 (95\% CI 0.77 to 1.09 ) for unrestrained passengers in vehicles with a front passenger airbag. For restrained passengers 60 years or older, the aRR was 1.02 (95\% CI 0.93 to 1.12 ) for passengers in vehicles without airbags and 1.06 (95\% CI 0.90 to 1.26) for passengers in vehicles with a front passenger airbag. Among restrained passengers 13-59 years, the rear seat appeared to offer no protection in cars with a front passenger airbag.

Using the same model that produced seat position estimates for table 2, we estimated the risk ratio of death of a restrained passenger compared with an unrestrained passenger (table 3). For a restrained child younger than 13 years compared with an unrestrained child the aRR was 0.44 (95\% CI 0.38 to 0.51 ) in the rear seat and 0.37 (95\% CI 0.32 to 0.44 ) in the front seat in vehicles with a front

\begin{tabular}{|c|c|c|c|c|}
\hline \multirow[b]{3}{*}{ Age group } & \multicolumn{2}{|l|}{ No passenger airbag } & \multicolumn{2}{|c|}{ Passenger airbag present } \\
\hline & Unrestrained (31996) & Restrained (20521) & Unrestrained (1557) & Restrained (2570) \\
\hline & aRR $(95 \% \mathrm{Cl})$ & aRR $(95 \% \mathrm{Cl})$ & aRR $(95 \% \mathrm{Cl})$ & aRR $(95 \% \mathrm{Cl})$ \\
\hline $\begin{array}{l}0-12 \text { years } \\
13-29 \text { years } \\
30-59 \text { years } \\
\geqslant 60 \text { years }\end{array}$ & $\begin{array}{l}0.71(0.64-0.79) \\
0.70(0.67-0.73) \\
0.75(0.70-0.81) \\
0.88(0.80-0.96)\end{array}$ & $\begin{array}{l}0.83(0.75-0.92) \\
0.82(0.77-0.87) \\
0.88(0.80-0.96) \\
1.02(0.93-1.12)\end{array}$ & $\begin{array}{l}0.53(0.41-0.70) \\
0.83(0.76-0.90) \\
0.89(0.80-0.98) \\
0.91(0.77-1.09)\end{array}$ & $\begin{array}{l}0.62(0.48-0.81) \\
0.96(0.88-1.06) \\
1.03(0.93-1.15) \\
1.06(0.90-1.26)\end{array}$ \\
\hline
\end{tabular}

aRR, adjusted risk ratio; $\mathrm{Cl}$, confidence interval. 


\begin{tabular}{|c|c|c|c|c|}
\hline \multirow[b]{3}{*}{ Age (years) } & \multicolumn{2}{|c|}{ No passenger airbag } & \multicolumn{2}{|c|}{ Passenger airbag present } \\
\hline & Front seat & Rear seat & Front seat & Rear seat \\
\hline & aRR $(95 \% \mathrm{Cl})$ & aRR $(95 \% \mathrm{Cl})$ & aRR $(95 \% \mathrm{Cl})$ & ARR $(95 \% \mathrm{Cl})$ \\
\hline $0-12$ & $0.45(0.39-0.51)$ & $0.53(0.47-0.59)$ & $0.37(0.32-0.44)$ & $0.44(0.38-0.51)$ \\
\hline $13-29$ & $0.43(0.40-0.46)$ & $0.50(0.47-0.55)$ & $0.36(0.32-0.41)$ & $0.42(0.37-0.47)$ \\
\hline $30-59$ & $0.43(0.39-0.48)$ & $0.51(0.45-0.57)$ & $0.36(0.31-0.41)$ & $0.42(0.36-0.48)$ \\
\hline$\geqslant 60$ & $0.61(0.54-0.69)$ & $0.71(0.63-0.81)$ & $0.51(0.44-0.59)$ & $0.59(0.51-0.69)$ \\
\hline
\end{tabular}

passenger airbag. In vehicles without a front passenger airbag, the aRR was 0.53 (95\% CI 0.47 to 0.59 ) for children in the rear seat and 0.45 (95\% CI 0.39 to 0.51 ) for children in the front seat. These estimates varied little by passenger age, except for the oldest passengers among whom restraints appeared to afford less protection. The aRR for death of a restrained passenger 60 years or older compared with an unrestrained passenger of the same age was 0.59 (95\% CI 0.51 to 0.69 ) in the rear seat and 0.51 (95\% CI 0.44 to 0.59 ) for passengers in the front seat in vehicles with a front passenger airbag. In vehicles without a front passenger airbag, the aRR increased to 0.71 (95\% CI 0.63 to 0.81 ) in the rear seat and 0.61 (95\% CI 0.54 to 0.69$)$ for passengers 60 years or older in the front seat.

\section{DISCUSSION}

On average, the risk of death was $21 \%$ lower among passengers in the rear seat compared with front seat passengers. This apparent protection varied with age, restraint use, and airbag presence. The rear seat seemed to offer the greatest protection to children 0-12 years. Children seated in the rear seat had a lower risk of death compared with front seat passengers whether or not they were restrained. Among adolescent and adult passengers, the rear seat offered less protection with increasing age and when restraints were used. Restraints offered more protection to both front and rear seat passengers in vehicles with a front passenger airbag. In addition, restraints offered greater protection to front seat passengers compared with rear seat passengers.

\section{Potential limitations of this study}

The limitations of the matched cohort design are the same as those of any other cohort study: possible bias due to confounding, measurement error (misclassification), and missing data. The matched cohort design can estimate risk ratios as we have done in this study, but absolute risks cannot be estimated using only data from matched sets with the study outcome.

Some data on restraint use, age, sex, or airbag status were missing for $16 \%$ of vehicles in our study sample. Analysis of complete records only relies on the assumption that data were missing at random. We used multiple imputation, which relies on the weaker assumption that data were missing at random conditional on the values of variables used for imputation. ${ }^{12}$ Bias could still be present if the pattern of missing values were strongly related to unmeasured aspects of crashes or passengers.

Information about restraint use may be misclassified in some police crash reports in FARS data. However, crashes that involve a passenger death are investigated more intensely than minor crashes. According to one study, the police report was $91 \%$ sensitive and $88 \%$ specific for the use of a restraint among all passengers when at least one passenger in the vehicle died. ${ }^{15}$ This suggests that our present study, which used data from passengers who crashed in the same vehicle with at least one dead passenger, may not be biased to an important degree due to misclassification of restraint use.

In our analysis, we added an interaction between seat position, restraint use, and front passenger airbag that should allow for the possibility that rear seat restraints improved over time (for example, through the addition of shoulder belts). This interaction term did not produce an important change in the estimates in our model.

\section{Comparison with other studies}

Evans and Frick used 1975-85 FARS data to estimate that among unrestrained occupants age 16 years and older in cars without airbags, the risk of death in the rear seat was $26 \%$ less compared with the front seat. ${ }^{1}$ Their estimate was similar to our estimates of risk reduction among unrestrained occupants in cars without airbags: $30 \%$ reduction among those age 13-29 years, 25\% reduction among those 30-59 years, and $12 \%$ reduction among those 60 years and older. They used a matched-pairs analysis that compared the outcomes of adults in the same vehicle. ${ }^{16}$ This method should control well for many vehicle and crash characteristics. ${ }^{9}$

Braver and colleagues used 1988-95 FARS data and estimated that the risk for death in the rear seat was 0.64 (95\% CI 0.61 to 0.67), compared with the front seat, for children younger than 13 years and 0.68 (95\% CI 0.67 to 0.69 ) for adolescents and adults. ${ }^{2}$ For rear seat passengers younger than 13 years compared with front seat passengers of the same age the risk for death was 0.47 (95\% CI 0.36 to 0.61 ) for unrestrained belted passengers and 0.35 (95\% CI 0.19 to 0.66 ) for restrained passengers in vehicles with a front passenger airbag. Their risk ratio estimates were all further from 1 than corresponding estimates in our study. They treated FARS data as if it were from a cohort study of all crashes, and the estimated risk ratios were not adjusted for crash severity or any other potential confounders.

In a previous cohort study, we used 1993-2000 data from the National Highway Traffic Safety Administration's Crashworthiness Data System to estimate that the risk of death in the rear seat was 39\% (95\% CI 19 to 54\%) less compared with the front seat. ${ }^{5}$ The confidence intervals in our previous study were wide and included the average $21 \%$ protective effect estimate of our current study; however, the confidence intervals from our current study (95\% CI 18 to $23 \%$ ) suggest that an average $39 \%$ reduction in the risk of death in the rear seat is unlikely. We suspect that our newer estimates, which compared passengers in the same vehicle, may be less subject to bias due to confounding.

Berg et al studied children younger than age 15 years who crashed in Utah, and used a cohort design to estimate that the relative odds of death or serious injury was 0.59 (95\% CI 0.50 to 0.63 ) for children in the rear seat compared with children in the front seat. ${ }^{3}$ In Berg's study, $45 \%$ of the 
children died or were seriously injured; since the odds ratio will be further from 1 than the risk ratio when the outcome is common, the odds ratio from that study is difficult to compare with the risk ratios from other studies. ${ }^{17} 18$

Durbin et al evaluated the effects of seating position and restraint use on the risk of serious injury to children younger than 16 years who were involved in crashes of insured vehicles in 15 US states from December 1998 through November 2002. ${ }^{19}$ In that study, children in the front seat had a $40 \%$ greater risk of injury compared with children in the rear seat $(\mathrm{OR}=1.4 ; 95 \%$ CI 1.2 to 1.7$)$. Their analysis did not control for crash characteristics.

Using a matched-pair analysis, Evans estimated rear seat belt restraint effectiveness in FARS data for 1975 through 1985. In those years only lap belts were available for rear seat occupants. Evans estimated that lap belts reduced the risk of death by $18 \% .{ }^{16}$ This does not agree well with our estimate of a $50 \%$ reduction in the risk of death. While the method used by Evans should control well for most vehicle and crash characteristics, it could not simultaneously control for age or sex. In the era of that study, the use of a rear seat belt was uncommon. A small amount of misclassification of unbelted subjects to the belted group would bias the aRR toward $1 .{ }^{6} \mathrm{~A}$ similar amount of misclassification would affect our current estimates less, as belt use is now common in the rear seat. ${ }^{\circ}$

\section{CONCLUSION}

We estimated that the rear seat passenger position may reduce the risk of death in a traffic crash by about $21 \%$. The estimates suggest that the rear seat offered the greatest protection to children $0-12$ years in cars with a front passenger airbag. The protective effect of the rear seat position decreased with increasing passenger age and with restraint use. The rear seat position offered essentially no protection to restrained adults in vehicles with front passenger airbags; for restrained adults, it appears that an airbag reduces the risk of death in the front seat to a degree that is about the same as that of the rear seat position. Restraints afforded greater protection to front seat passengers compared with rear seat passengers and more protection to passengers in vehicles with a front passenger airbag.

Previous studies have reported that the rear seat was safer for people of all ages; thus seating a young child in the rear has often meant that older children and adults had to assume an increased risk of death by sitting in the front. Our results suggest that when front passenger airbags are present and passengers are restrained, putting adults in front and children in back enhances child safety without sacrificing adult safety.

\section{ACKNOWLEDGEMENTS}

We wish to thank Christopher Mack for programming help with the data files.

\footnotetext{
Authors' affiliations

K M Smith, P Cummings, Harborview Injury Prevention and Research Center, Seattle, WA, USA

K M Smith, Department of Pediatrics, University of Washington, Seattle, WA, USA

P Cummings, Department of Epidemiology, University of Washington, Seattle, WA, USA

Funding/Support: this work was supported by grant R49/CE000197 from the Centers for Disease Control and Prevention, Atlanta, GA. The funding organization had no role in the design and conduct of the study, analysis and interpretation of the data, preparation, review, and approval of the manuscript, or the decision to submit the manuscript for publication.

Competing interests: none.
}

\section{Key points}

- On average, the risk of death was $21 \%$ lower among passengers in the rear seat compared with front seat passengers. The rear seat offered the greatest protection to children 0-12 years.

- Restraints offered more protection to both front and rear seat passengers in vehicles with a front passenger airbag. In addition, restraints offered greater protection to front seat passengers compared with rear seat passengers.

- Previous studies reported that the rear seat was safer for people of all ages; thus seating a young child in the rear has often meant that older children and adults had to assume an increased risk of death by sitting in the front. Our results suggest that when passenger airbags are present and passengers are restrained, putting adults in front and children in back enhances child safety without sacrificing adult safety.

Drs Smith and Cummings are responsible for the study conception and design, the drafting and critical revising of the paper for important intellectual content, and the final approval of the version to be published. Drs Smith and Cummings are the guarantors of the paper. The guarantors accept full responsibility for the work and/or conduct of the study, had access to the data, and controlled the decision to publish the paper.

\section{REFERENCES}

1 Evans L, Frick MC. Seating position in cars and fatality risk. Am J Public Health 1988;78:1456-8.

2 Braver ER, Whitfield R, Ferguson SA. Seating position and children's risk of dying in motor vehicle crashes. Inj Prev 1998;4:181-7.

3 Berg MD, Cook L, Corneli H, et al. Effect of seat position and restraint use on injuries to children in motor vehicle crashes. Pediatrics 2000;105:831-5.

4 Glass RJ, Segui-Gomez M. Graham JD. Child passenger safety: decisions about seating position, air bag exposure, and restraint use. Risk Anal 2000;20:521-7.

5 Smith KM, Cummings $P$. Passenger seating position and the risk of passenger death or injury in traffic crashes. Accid Anal Prev 2004;36:257-60.

6 Cummings $P$, Wells JD, Rivara FP. Estimating seat belt effectiveness using matched-pair cohort methods. Accid Anal Prev 2003:35:143-9.

7 Cummings $\mathbf{P}$, McKnight B, Weiss NS. Matched-pair cohort methods in traffic crash research. Accid Anal Prev 2003;35:131-41.

8 National Highway Traffic Safety Administration. Traffic Safety Facts 2000: a compilation of motor vehicle crash data from the fatality analysis reporting system and the general estimates system. Washington, DC: National Highway Traffic Safety Administration, 2001.

9 Cummings P, McKnight B, Greenland S. Matched cohort methods in injury research. Epidemiol Rev 2003;25:43-50.

10 Vindicator 2001 (computer program), Release 1, Arlington, VA. Highway Loss Data Institute. 2001

11 Harborview Injury Prevention and Research Center. Data on alcohol, seatbelts and airbags added to FARS. Available at http:// depts.washington.edu/hiprc/FARS/FARSintro.html (accessed December 2005).

12 Schafer JL. Analysis of incomplete multivariate data. New York: Chapman \& Hall, 1997, 108-16, 257-75.

13 Greenland S. Dose-response and trend analysis in epidemiology: alternatives to categorical analysis. Epidemiology 1995;6:356-65.

14 Stata Statistical Software: Release 9.1. Stata Corporation, TX: College Station, 2004

15 Schiff M, Cummings P. Comparison of reporting of seat belt use by police and crash investigators: variation in agreement by injury severity. Accid Anal Prev 2004;36:961-5.

16 Evans L. Rear seat restraint system effectiveness in preventing fatalities. Accid Anal Prev 1988;20:129-36.

17 Altman DG, Deeks JJ, Sackett DL. Odds ratios should be avoided when events are common. BMJ 1998;317:1318.

18 McNutt LA, Wu C, Xue X, et al. Estimating the relative risk in cohort studies and clinical trials of common outcomes. Am J Epidemiol 2003;157:940-3.

19 Durbin D, Chen I, Smith R, et al. Effects of seating position and appropriate restraint use on the risk of injury to children in motor vehicle crashes. Pediatrics 2005; 115:e305-9. 